\title{
Assessment of Proportion of Hidden Patients Having Symptoms of Overactive Bladder and Why Has It Been Hidden in Female Outpatients Admitted to Hospital
} \author{
Surgery \\ ${ }^{1}$ Department of Urology, Celal Bayar University, Faculty of Medicine, Manisa, Turkey \\ ${ }^{2}$ Department of Urology, Dokuz Eylül University, Faculty of Medicine, İzmir, Turkey \\ ${ }^{3}$ Urology Clinic, Uşak State Hospital, Uşak, Turkey \\ ${ }^{4}$ Department of Urology, İzmir Bozyaka Training and Research Hospital, İzmir, Turkey \\ ${ }^{5}$ Urology Clinic, Acıpayam State Hospital, Denizli, Turkey \\ ${ }^{6}$ Department of Urology, Pamukkale University, Faculty of Medicine, Denizli, Turkey \\ ${ }^{7}$ Department of Urology, İzmir Tepecik Training and Research Hospital, İzmir, Turkey
}

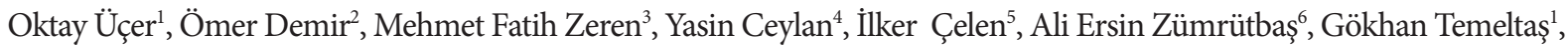
Ozan Bozkurt ${ }^{2}$, Bülent Günlüsoy ${ }^{4}$, Orçun Çelik ${ }^{7}$, Gökhan Ekin 7 , Oğuz Mertoğlu; Aegean Study Group of Society of Urological

\begin{abstract}
Purpose: To determine the proportion of patients with undetected symptoms of overactive bladder by using the overactive bladder-validated $8(\mathrm{OAB}-\mathrm{V} 8)$ screening questionnaire and investigate these symptoms were undetected in female patients who were hospitalized.

Methods: We invited 2,250 female patients hospitalized in the Aegean region of Turkey to answer a self-administered questionnaire. The questionnaire included questions on evidence of lower urinary tract symptoms (OAB-V8), relevant medical history, and demographic data. Patients with a total OAB-V8 score $\geq 8$ were defined as having OAB symptoms.

Results: The proportion of patients with OAB symptoms in this study was $40.6 \%$. Nearly $57 \%$ of the patients with OAB symptoms had not been previously admitted to any hospital for lower urinary tract symptoms (LUTS). The two most common reasons why women with OAB symptoms did not admit themselves to a hospital because of LUTS were as follows: "I did not think I had a disease" and "The symptoms did not bother me," with a response rate of $74.7 \%$. The mean OAB-V8 scores of the patients with these two responses were significantly lower than those of the other patients $(\mathrm{P}<0.001)$.

Conclusions: This is the first study to demonstrate a significant proportion of women with undetected OAB symptoms. The main reasons the women did not admit themselves to a hospital were their unawareness of the disease and because the LUTS were not bothersome. Public awareness programs on this disease may resolve this problem.
\end{abstract}

Keywords: Symptoms; Urinary Bladder, Overactive; Diagnosis

- Research Ethics: The study protocol was approved by the ethics committee of Celal Bayar University (approval number: 20478486-320).

- Conflict of Interest: No potential conflict of interest relevant to this article was reported.

\section{INTRODUCTION}

Overactive bladder $(\mathrm{OAB})$ is a common disorder that adversely affects the quality of life of patients and brings a heavy socioeconomic burden [1]. OAB was first described by Paul Abrams in 1997 (quoted from [2]). According to the International Con-

Corresponding author: Oktay Üçer (iD http://orcid.org/0000-0001-7912-0408 Department of Urology, Celal Bayar University, Faculty of Medicine, No: 173, Merkez, 45030 Manisa, Turkey

E-mail: uceroktay@yahoo.com / Tel: +905052114618 / Fax: +902362338040

Submitted: August 7, 2015 / Accepted after revision: September 8, 2015 
tinence Society, it is characterized by urinary urgency, with or without urge incontinence, usually with frequency and nocturia, in the absence of causative infection or pathological conditions [3]. Earlier studies reported the prevalence of OAB in a wide spectrum, ranging from $2 \%$ to $53 \%$ [4-14]. Unfortunately, these studies had methodological limitations $[4,5,7,8,10,12,13]$ or were not population based $[6,9,11,14]$. Despite the fact that $\mathrm{OAB}$ has a significant impact on patients' quality of life and daily activities, it is frequently unreported and underdiagnosed [15]. This is the other reason of the discrepant results of previous reports about prevalence. This lack of recognition of $\mathrm{OAB}$ can be associated with patients' lack of understanding of the disorder, besides the fact that they tend not to talk about their symptoms or associate them with aging [16]. Self-assessment questionnaires and registries are useful for the diagnosis. However, these tests are not generally applied in daily practice [15].

The overactive bladder questionnaire (OAB-q) was first developed by Coyne et al. [17] in 2002 for assessment of symptoms and quality of life of patients with OAB. Subsequent studies developed shorter forms of the OAB-q. Overactive bladdervalidated $8(\mathrm{OAB}-\mathrm{V} 8)$ is one of these shorter forms and was translated into 14 languages in 2006 by Acquadro et al. [18]. The aim of our study was to determine the proportion of female patients with undetected $O A B$ symptoms who refer to hospitals for other diseases by using the OAB-V8 questionnaire and to investigate why these patients did not mention about their symptoms.

\section{MATERIALS AND METHODS}

A multicenter, observational epidemiological study was conducted between December 2013 and August 2014. Female patients aged $\geq 18$ years who were admitted to 4 different hospitals in the Aegean region of Turkey were asked to answer a selfadministered questionnaire. The study questionnaire was developed by the study team and consisted of four parts as follows: (1) sociodemographic data; (2) OAB-V8 (Turkish version of OAB-V8 validated by Tarcan et al. [19]); (3) 2 questions about the treatment received by patients with $\mathrm{OAB}$ symptoms who previously referred to a hospital for their symptoms; (4) two questions for patients with $\mathrm{OAB}$ symptoms who had not been previously admitted to any hospital for their symptoms (Table 1). Patients with undetected $O A B$ symptoms were defined as those having $\mathrm{OAB}-\mathrm{V} 8$ scores $\geq 8$ who had not been admitted to any hospital because of LUTS. These patients were asked why
Table 1. The questions administered to the patients with $\mathrm{OAB}$ V8 scores $\geq 8$

Have you been admitted to any hospital for these symptoms before? Yes or No

If your answer is yes, please continue.

1. Which clinics did you admit yourself for these complaints?

2. Did you take any medications?

If your answer is no, please continue.

1. Why did you not admit yourself to any hospital for these complaints?

2. Which clinic do you think you should go to?

OAB-V8, overactive bladder-validated 8.

they had not admitted themselves to any hospital because of the aforementioned complaints. They were asked to choose the most appropriate answer. The study protocol was approved by the local ethics committee (approval number: 20478486-320).

Statistical analysis was performed by using SPSS ver. 16.0 (SPSS Inc., Chicago, IL, USA). The patients were divided into 5 groups according to age, and the proportion of patients with OAB-V8 scores $\geq 8$ in these age groups was calculated. The patients with OAB V8 scores $\geq 8$ were divided into two groups according to whether or not they had been admitted to a hospital because of these symptoms. The demographic features of the 2 groups were statistically compared. The patients with undetected $\mathrm{OAB}$ symptoms were divided into 6 groups according to their responses to the question, "Why did you not admit yourself to any hospital because of these symptoms before?" The 6 groups were compared in terms of OAB V8 scores. A P-value $<0.05$ was considered statistically significant.

\section{RESULTS}

We enrolled 2,250 female patients with a mean age (range) of $41.2 \pm 15.4$ years (18-95 years) who agreed to participate in the study. The proportion of patients with OAB symptoms in this study was $40.6 \%$. A strong positive correlation was found between age and OAB-V8 score $(\mathrm{P}<0,001, \mathrm{r}=0.42)$. Table 2 shows a comparison of demographic features between the patients with OAB V8 scores of $\geq 8$ (group 1) and $<8$ (group 2). Statistically significant differences in mean age, age range, marital status, educational level, work status, and living status were found between the two groups $(\mathrm{P}<0.001)$. Of the patients with undetected OAB symptoms (group 3), 57\% had newly diagnosed $\mathrm{OAB}$ and $43 \%$ (group 4) had been previously admitted to a hospital because of OAB symptoms. Table 3 shows a com- 
Table 2. Comparison of demographic features between the patients in the two groups according to OAB-V8 scores

\begin{tabular}{|c|c|c|c|}
\hline \multirow{2}{*}{ Variable } & \multicolumn{2}{|c|}{ OAB-V8 score } & \multirow{2}{*}{ P-value } \\
\hline & $\geq 8$ (group 1$)$ & $<8($ group 2$)$ & \\
\hline Number & 914 & 1,334 & \\
\hline Age (yr) & $49.07 \pm 14.13$ & $39.93 \pm 14.48$ & $<0.001$ \\
\hline $\begin{array}{l}\text { Age range } \\
<30 \\
30-39 \\
40-49 \\
50-59 \\
>59\end{array}$ & $\begin{array}{l}103(16.7) \\
119(28.3) \\
254(49.2) \\
225(59.1) \\
213(68.1)\end{array}$ & $\begin{array}{l}515(83.3) \\
301(71.7) \\
262(50.8) \\
156(40.9) \\
100(31.9)\end{array}$ & $<0.001$ \\
\hline $\begin{array}{l}\text { Marital status } \\
\text { Married } \\
\text { Single } \\
\text { Divorced }\end{array}$ & $\begin{array}{l}604(43.7) \\
152(24.3) \\
157(64.6)\end{array}$ & $\begin{array}{r}776(56.3) \\
472(75.7) \\
86(35.4)\end{array}$ & $<0.001$ \\
\hline $\begin{array}{l}\text { Education } \\
\text { Primary school } \\
\text { Secondary school } \\
\text { High school } \\
\text { University }\end{array}$ & $\begin{array}{l}394(55.1) \\
116(46.7) \\
195(35.1) \\
201(27.9)\end{array}$ & $\begin{array}{l}320(44.9) \\
132(53.3) \\
360(64.9) \\
517(72.1)\end{array}$ & $<0.001$ \\
\hline $\begin{array}{l}\text { Work status } \\
\text { Student } \\
\text { Working } \\
\text { Retired } \\
\text { Housewife }\end{array}$ & $\begin{array}{r}35(11.3) \\
321(37.8) \\
102(59.3) \\
456(49.5)\end{array}$ & $\begin{array}{r}273(88.7) \\
526(62.2) \\
70(40.7) \\
465(50.5)\end{array}$ & $<0.001$ \\
\hline $\begin{array}{l}\text { Income level (TL) } \\
\quad<1,000 \\
1,000-3,000 \\
3,000-5,000 \\
>5,000\end{array}$ & $\begin{array}{r}429(40.4) \\
429(40.5) \\
42(43.7) \\
13(43.3)\end{array}$ & $\begin{array}{r}632(59.6) \\
630(59.5) \\
54(56.3) \\
17(56.7)\end{array}$ & 0.900 \\
\hline $\begin{array}{l}\text { Living status } \\
\text { Village } \\
\text { Town } \\
\text { City }\end{array}$ & $\begin{array}{l}130(54.6) \\
196(42.5) \\
584(37.8)\end{array}$ & $\begin{array}{l}108(45.4) \\
265(57.5) \\
960(62.2)\end{array}$ & $<0.001$ \\
\hline
\end{tabular}

Values are presented as mean \pm standard deviation or number (\%). OAB-V8, overactive bladder-validated 8; TL, Turkish Lira.

parison of demographic features between the patients in group 3 and those in group 4. Although significant differences in mean age, age range, work status, and living status were found between the patients in group 3 and those in group 4, no significant differences in marital status, educational level, and income level were found between the groups (Table 3).

The ratio of the reasons the $\mathrm{OAB}$ symptoms were undetected, and the mean ages and mean OAB V8 scores for different causes of the patients are provided in Table 4. The two most common reasons why the women with $\mathrm{OAB}$ symptoms did not admit themselves to a hospital because of LUTS were as follows: (1) "I did not think I had a disease." and (2) "The symptoms did
Table 3. Comparison of demographic features between the patients in the 2 groups according to their responses to the question, "Have you been admitted to any hospital because of $\mathrm{OAB}$ symptoms?”

\begin{tabular}{|c|c|c|c|}
\hline \multirow{2}{*}{ Variable } & \multicolumn{2}{|c|}{ OAB-V8 score $\geq 8$} & \multirow{2}{*}{ P-value } \\
\hline & No (group 3) & Yes (group 4) & \\
\hline Number & 521 & 393 & \\
\hline Age (yr) & $46.40 \pm 14.82$ & $50.90 \pm 14.43$ & $<0.001$ \\
\hline $\begin{array}{l}\text { Age range } \\
<30 \\
30-39 \\
40-49 \\
50-59 \\
>59\end{array}$ & $\begin{array}{r}65(57.6) \\
150(60.0) \\
118(54.4) \\
101(47.5) \\
87(72.0)\end{array}$ & $\begin{array}{r}48(42.4) \\
100(40.0) \\
99(45.6) \\
112(52.5) \\
34(28.0\end{array}$ & $<0.001$ \\
\hline $\begin{array}{l}\text { Marital status } \\
\text { Married } \\
\text { Single } \\
\text { Divorced }\end{array}$ & $\begin{array}{r}345(57.4) \\
91(55.5) \\
85(57.5)\end{array}$ & $\begin{array}{r}257(42.6) \\
73(44.5) \\
63(42.5)\end{array}$ & 0.810 \\
\hline $\begin{array}{l}\text { Education } \\
\text { Primary school } \\
\text { Secondary school } \\
\text { High school } \\
\text { University }\end{array}$ & $\begin{array}{r}213(56.3) \\
56(51.0) \\
106(53.9) \\
146(63.8)\end{array}$ & $\begin{array}{r}165(43.7) \\
54(49.0) \\
91(46.1) \\
83(36.2)\end{array}$ & 0.100 \\
\hline $\begin{array}{l}\text { Work status } \\
\text { Student } \\
\text { Working } \\
\text { Retired } \\
\text { House wife }\end{array}$ & $\begin{array}{r}37(77.1) \\
182(57.6) \\
48(45.8) \\
254(56.6)\end{array}$ & $\begin{array}{r}11(22.9) \\
134(42.4) \\
53(54.2) \\
195(43.4)\end{array}$ & $<0.001$ \\
\hline $\begin{array}{l}\text { Income level (TL) } \\
\quad<1,000 \\
1,000-3,000 \\
3,000-5,000 \\
>5,000\end{array}$ & $\begin{array}{r}238(56.6) \\
256(58.9) \\
21(46.7) \\
6(46.2)\end{array}$ & $\begin{array}{r}183(43.4) \\
179(41.1) \\
24(53.3) \\
7(53.8)\end{array}$ & 0.610 \\
\hline $\begin{array}{l}\text { Living status } \\
\text { Village } \\
\text { Town } \\
\text { City }\end{array}$ & $\begin{array}{r}77(61.6) \\
103(54.5) \\
341(56.9)\end{array}$ & $\begin{array}{r}48(38.4) \\
86(45.5) \\
259(43.1)\end{array}$ & $<0.05$ \\
\hline
\end{tabular}

Values are presented as mean \pm standard deviation or number (\%). OAB-V8, overactive bladder-validated 8; TL,Turkish Lira.

not bother me." The mean OAB-V8 scores of the patients with these 2 responses were significantly lower than those of the patients with other responses (11.34 vs. $16.29, \mathrm{P}<0.001)$. Of the patients who responded to the question, "Why did you not admit yourself to a hospital for these symptoms before?" $74.7 \%$ gave the 2 responses.

\section{DISCUSSION}

In the present study, our objective was to determine the propor- 
Table 4. Mean OAB-V8 scores and ages according to the patients' responses

\begin{tabular}{lccc}
\hline Why did you not refer to a hospital because of these symptoms? & No. of patients & Age (yr) & OAB-V8 score \\
\hline I did not think it was a disease. & $209(40.1)$ & $46.45 \pm 14.43$ & $12.73 \pm 6.23$ \\
The symptoms did not bother me. & $183(35.1)$ & $45.12 \pm 15.04$ & $9.62 \pm 5.13$ \\
I was ashamed to seek treatment. & $73(14.0)$ & $48.01 \pm 13.45$ & $16.34 \pm 7.13$ \\
I did not know where I should go to. & $31(5.9)$ & $50.41 \pm 15.42$ & $14.56 \pm 5.71$ \\
I had no time. & $20(3.8)$ & $56.09 \pm 12.13$ & $17.13 \pm 7.60$ \\
Others & $5(0.9)$ & $50.51 \pm 13.34$ & $18.22 \pm 5.11$ \\
\hline
\end{tabular}

Values are presented as number (\%) or mean \pm standard deviation.

OAB-V8, overactive bladder-validated 8 .

tion of female patients with undetected OAB symptoms who attended tertiary hospitals because of varied complaints referred to different departments (urology, gynecology, ophthalmology, internal medicine, general surgery, etc.) in the Aegean region of Turkey by using a self-administered questionnaire. Cheung et al. [1] reported that the prevalence of OAB in women aged 18 to 70 years (mean, 42.2 years) was $30 \%$. The ages of the patients in their study were similar to those of our patients. The proportion of patients with OAB symptoms in our study was higher than that of patients $\mathrm{OAB}$ in the previous study. Two reasons of this difference may be that our study group consisted of patients with different complaints and our study was not epidemiological. Previous epidemiological studies consistently report increased prevalence of OAB with age [20]. Similarly, the present study showed that the proportion of female patients with $\mathrm{OAB}$ symptoms increased with age. The demographic data of groups 1 and 2 were compared, and statistically significant differences were found between the 2 groups, except for income status (Table 1). Overall, the findings of this statistical analysis show that aging is an important factor of $\mathrm{OAB}$ symptoms. For example, the proportion of patients with $\mathrm{OAB}$ symptoms was lower among single women than among divorced and married women, and among female students and working women than among housewives and retired women (Table 1).

We used the OAB-V8 questionnaire in face-to-face interviews with patients to evaluate $\mathrm{OAB}$ symptoms. This type of data collection was reported to be more accurate than the use of postal questionnaires and telephone interviews because the questions can be clarified before answering [21]. We found that $57 \%$ (group 3) of the 914 patients with OAB symptoms had not been admitted to a hospital because of their LUTS, whereas 393 patients (group 4) had been admitted to a hospital for their symptoms. We compared demographic features between the patients in group 3 and those in group 4 . No statistically significant differences in marital status, educational level, and income level were found. The mean age of the patients in groups 3 and 4 were 46.4 and 50.9 years $(\mathrm{P}<0.001)$. The work status of the patients with $\mathrm{OAB}$ symptoms was evaluated, and a statistically significant difference was found between the patients in group 3 and those in group 4 . This discrepancy depends on the difference in the number of students between the 2 groups. Group 3 had more students than group 4 , and the difference was statistically significant (Table 3). Overall, these findings show that younger patients with $\mathrm{OAB}$ symptoms do not prefer to go to a hospital for their symptoms. When we investigated the living status of the patients in groups 3 and 4 , we found that most of the patients living in the village did not attend a hospital because of LUTS (Table 3). This may be due transportation difficulties from the villages to hospitals.

The two most common responses that accounted for $74.7 \%$ of all the responses to the question, "Why have you not referred to a hospital because of these symptoms before?," were "I think I did not have a disease." and "The symptoms did not bother me." (Table 4). The mean OAB-V8 score of the patients who did not think the LUTS were bothersome was 9.6. The mean OABV8 score of the patients who answered, "I did not think it was a disease," was 12.79. Coyne et al. [22] reported that the model identifying patients with a diagnosis of probable $\mathrm{OAB}$ had a sensitivity and specificity of 98.0 and 82.7 , respectively. They found that for OAB-V8 scores $\geq 8$, the odds ratio for probable OAB was 95.7 (95\% confidence interval, 29.3-312.4). They also recommended that the OAB-V8 performed well in helping clinicians identify patients with bothersome OAB symptoms in a primary care setting. On the other hand, Muhilan et al. [23] reported that for OAB screening, an optimum OAB-V8 screen- 
ing score $>12$ had a sensitivity of $94.7 \%$ and a specificity of $83.4 \%$. In a study in Turkey, Tarcan et al. [19] found that the sensitivity and specificity of OAB-V8 scores $>8.5$ for the diagnosis of OAB were $90 \%$ and $59 \%$, respectively, and those of OAB-V8 scores $>11.5$ were $80 \%$ and $78 \%$, respectively. In our study, OAB V8 scores $\geq 8$ were used in identifying patients with $\mathrm{OAB}$ symptoms. With this cutoff OAB V8 score, we found that $34.9 \%$ of the patients with $\mathrm{OAB}$ symptoms did not consider their LUTS bothersome. Cetinel et al. [21] evaluated only the prevalence of undetected urinary incontinence (UI) in women in Turkey and found that although the crude prevalence of female UI was found to be high (36\%), more than half (53\%) of incontinent women had nonbothersome UI. They also reported that most incontinent female patients did not seek medical help, whereas the degree of discomfort due to the symptoms was found to be the only independent factor that increased the help-seeking behavior of incontinent women. We suggest that this cut off OAB-V8 score for the diagnosis of OAB should be reconsidered according to geographical region.

Despite the high prevalence of $\mathrm{OAB}$, many afflicted patients remain undiagnosed or untreated [1]. We found that $57 \%$ of the patients with $\mathrm{OAB}$ symptoms in our study population remained undiagnosed. The most common responses aside from the aforementioned two most common ones were "Ashamed to seek treatment," "I did not know where I should go." and "I had no time." We think that these patients did not have enough information about OAB and LUTS. To avoid this situation, primary care practitioners should evaluate patients with LUTS by using self-administered questionnaires. Patients with $\mathrm{OAB}$ symptoms should be given information about $\mathrm{OAB}$ and, if necessary, referred to secondary or tertiary hospitals.

Our present study has some methodological limitations, the most important of which is its being not population based. On the other hand, the large number of participating centers, including universities, and training and research hospitals, in the Aegean region of Turkey makes our study valuable. The other important limitation of our study is that the subjects were not evaluated for possible urinary tract infection, genitourinary cancers, contracted bladder, loop diuretics, pregnancy, and puerperal conditions. Future studies about this topic may evaluate the above-mentioned conditions as exclusion criteria.

In conclusion, the high proportion of patients with $\mathrm{OAB}$ symptoms in our study suggests that the needs of many of them may not have been met by their primary care providers. Patients with LUTS should be given information about OAB and
LUTS by primary care providers. We also suggest that this information should be provided to people via the Internet and media by societies in order to increase their awareness. When $\mathrm{OAB}$-V8 (score $\geq 8$ ) was used in the diagnosis of $\mathrm{OAB}$, one of every three patients with $\mathrm{OAB}$ symptoms did not consider their disorder bothersome. Further studies should reevaluate these patients with further tests and should reconsider the threshold OAB-V8 score.

\section{REFERENCES}

1. Cheung WW, Khan NH, Choi KK, Bluth MH, Vincent MT. Prevalence, evaluation and management of overactive bladder in primary care. BMC Fam Pract 2009;10:8.

2. The overactive bladder: from basic science to clinical management consensus conference. Proceedings. London, England, June 29, 1997. Urology 1997;50(6A Suppl):1-114.

3. Abrams P, Cardozo L, Fall M, Griffiths D, Rosier P, Ulmsten U, et al. The standardisation of terminology of lower urinary tract function: report from the Standardisation Sub-committee of the International Continence Society. Neurourol Urodyn 2002;21:167-78.

4. Milsom I, Abrams P, Cardozo L, Roberts RG, Thuroff J, Wein AJ. How widespread are the symptoms of an overactive bladder and how are they managed? A population-based prevalence study. BJU Int 2001;87:760-6.

5. Stewart WF, Van Rooyen JB, Cundiff GW, Abrams P, Herzog AR, Corey R, et al. Prevalence and burden of overactive bladder in the United States. World J Urol 2003;20:327-36.

6. Temml C, Heidler S, Ponholzer A, Madersbacher S. Prevalence of the overactive bladder syndrome by applying the International Continence Society definition. Eur Urol 2005;48:622-7.

7. Homma Y, Yamaguchi O, Hayashi K; Neurogenic Bladder Society Committee. An epidemiological survey of overactive bladder symptoms in Japan. BJU Int 2005;96:1314-8.

8. Teloken C, Caraver F, Weber FA, Teloken PE, Moraes JF, Sogari PR, et al. Overactive bladder: prevalence and implications in Brazil. Eur Urol 2006;49:1087-92.

9. Moorthy P, Lapitan MC, Quek PL, Lim PH. Prevalence of overactive bladder in Asian men: an epidemiological survey. BJU Int 2004; 93:528-31.

10. Corcos J, Schick E. Prevalence of overactive bladder and incontinence in Canada. Can J Urol 2004;11:2278-84.

11. Lapitan MC, Chye PL; Asia-Pacific Continence Advisory Board. The epidemiology of overactive bladder among females in Asia: a questionnaire survey. Int Urogynecol J Pelvic Floor Dysfunct 2001; 
12:226-31.

12. Chen GD, Lin TL, Hu SW, Chen YC, Lin LY. Prevalence and correlation of urinary incontinence and overactive bladder in Taiwanese women. Neurourol Urodyn 2003;22:109-17.

13. Zhang W, Song Y, He X, Huang H, Xu B, Song J. Prevalence and risk factors of overactive bladder syndrome in Fuzhou Chinese women. Neurourol Urodyn 2006;25:717-21.

14. Parazzini F, Lavezzari M, Arbitani W. Prevalence of overactive bladder and urinary incontinence. J Fam Pract 2002;51:1072-5.

15. Lugo Salcedo F, Sanchez Borrego R; G.U.I.A.S Group. Assessment of female prevalence of overactive bladder $(\mathrm{OAB})$ in Barcelona using a self-administered screening questionnaire: the Cuestionario de Autoevaluación del Control de la Vejiga (CACV). Int Urogynecol J 2013;24:1559-66.

16. Garcia Matres MJ, Brenes Bermudez FJ. Diagnosis and management of patients with overactive bladder syndrome in urology clinics and general practitioner clinics in Spain. Arch Esp Urol 2007; 60:15-21.

17. Coyne K, Revicki D, Hunt T, Corey R, Stewart W, Bentkover J, et al. Psychometric validation of an overactive bladder symptom and health-related quality of life questionnaire: the OAB-q. Qual Life
Res 2002;11:563-74.

18. Acquadro C, Kopp Z, Coyne KS, Corcos J, Tubaro A, Choo MS, et al. Translating overactive bladder questionnaires in 14 languages. Urology 2006;67:536-40.

19. Tarcan T, Mangır N, Ozgur MO, Akbal C. OAB-V8 overactive bladder questionnaire validation study. Urology Bull 2012;21:113-6.

20. Tyagi P, Tyagi V, Qu X, Lin HT, Kuo HC, Chuang YC, et al. Association of inflammaging (inflammation + aging) with higher prevalence of OAB in elderly population. Int Urol Nephrol 2014;46:871-7. 21. Cetinel B, Demirkesen O, Tarcan T, Yalcin O, Kocak T, Senocak M, et al. Hidden female urinary incontinence in urology and obstetrics and gynecology outpatient clinics in Turkey: what are the determinants of bothersome urinary incontinence and help-seeking behavior? Int Urogynecol J Pelvic Floor Dysfunct 2007;18:659-64.

22. Coyne KS, Zyczynski T, Margolis MK, Elinoff V, Roberts RG. Validation of an overactive bladder awareness tool for use in primary care settings. Adv Ther 2005;22:381-94.

23. Muhilan Ap, S Sivaprakasam, Dublin N, S Rampal, Razack Ah, Thun Th, et al. Construction and validation of a Malay version of the overactive bladder screener for assessing urinary tract symptoms in a Malaysian population. J Health Transl Med 2009;12:74-82. 